
Клиническое наблюдение

\author{
А.Е. Комлев ${ }^{凶}$, М.А. Муксинова, М.А. Саидова, Э.В. Курилина, Т.Э. Имаев \\ Институт клинической кардиологии им. А.А. Мясникова ФГБУ «Национальный медицинский исследовательский центр кардиологии» \\ Минздрава России, Москва, Россия
}

\title{
Аннотация
}

Авторы приводят клиническое наблюдение вторичного синдрома Такоцубо после транскатетерной имплантации аортального клапана,

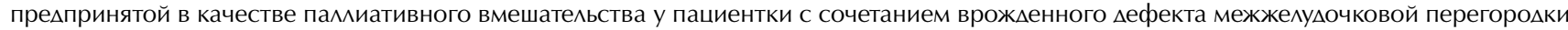

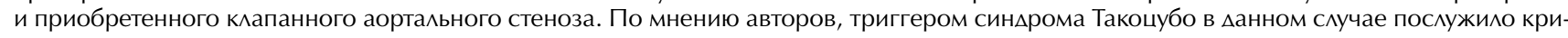
тическое изменение внутрисердечной гемодинамики при ятрогенном воздействии на степень межжелудочкового шунтирования крови.

КАючевые слова: синдром Такоцубо, дефект межжелудочковой перегородки, транскатетерная имплантация аортального клапана ияя цитирования: Комлев А.Е., Муксинова М.А., Саицова М.А., Курияина Э.В., Имаев Т.Э. Синдром Такоцубо после палмиативной транскатетерной коррекции приобретенного аортального стеноза у пациентки с врожАенным дефектом межжелудочковой перегородки. КАиническое наблюдение. Терапевтический архив. 2021; 93 (9): 1078-1085. DOI: 10.26442/00403660.2021.09.201031

\section{Takotsubo syndrome after palliative transcatheter treatment of acquired aortic stenosis in patient with congenital ventricular septal defect. Case report}

\author{
Alexey E. Komlev ${ }^{凶}$, Marina D. Muksinova, Marina A. Saidova, Ella V. Kurilina, Timur E. Imaev \\ Myasnikov Institute of Clinical Cardiology, National Medical Research Center of Cardiology, Moscow, Russia
}

\section{Abstract}

The authors report the clinical case of secondary Takotsubo syndrome developed after transcatheter aortic valve replacement that was performed in compassionate manner in female patient with combination of congenital ventricular septal defect and acquired severe aortic stenosis. In the team's view, Takotsubo syndrome was triggered with profound changes of intracardial hemodynamics subsequent to iatrogenic impairment of preexisting interventricular shunt.

Keywords: Takotsubo syndrome, ventricular septal defect, transcatheter aortic valve replacement

For citation: Komlev AE, Muksinova MD, Saidova MA, Kurilina EV, Imaev TE. Takotsubo syndrome after palliative transcatheter treatment of acquired aortic stenosis in patient with congenital ventricular septal defect. Case report. Terapevticheskii Arkhiv (Ter. Arkh.). $2021 ; 93$ (9): $1078-1085$. DOI: $10.26442 / 00403660.2021 .09 .201031$

\section{Введение}

С момента первого упоминания синдрома Такоцубо (СТ) прошло более 25 лет, однако до сих пор ведутся дискуссии о его нозологической характеристике и патогенезе, отсутствуданным, распространенность составляет примерно 1-3\% среди всех пациентов $[1,2]$ и 5-6\% среди женщин с подозрением на инфаркт миокарда с подъемом сегмента $S T$ [3].

СТ традиционно ассоциировался с перенесенным психоэмоциональным стрессом («синдром разбитого сердца»). Однако в последнее время большое внимание уделяется соматическим детерминантам стресса, наблюдаемым не реже чем психологические причины стрессового состояния ют общепринятые рекомендации по лечению. По разным

(36,0\% против 27,7\%) [4]. Также важное значение имеют ятрогенные причины развития синдрома, например введение симпатомиметиков, в том числе в ходе реанимационных мероприятий, которые также могут привести к развитию CT $[5,6]$. Учитывая предполагаемую роль катехоламинов в патофизиологии стрессиндуцированной кардиомиопатии, вынужденное использование положительных инотропных агентов отягощает клиническое течение СТ [7].

Представляем собственное наблюдение пациентки с тяжелым комбинированным пороком - врожденным подклапанным дефектом межжелудочковой перегородки (ДМЖП) и тяжелым дегенеративным аортальным стенозом (АС). Транскатетерная имплантация аортального клапана (АК) в

Информация об авторах / Information about the authors

\footnotetext{
Комлев Алексей Евгеньевич - кардиолог отА. сердечно-сосудистой хирургии. Тел.: +7(916)223-53-24; e-mail: pentatonika@bk.ru; ORCID: 0000-0001-6908-7472
}

Муксинова Марина Аамировна - кардиолог отА. сердечной недостаточности и заболеваний миокарда. ORCID: 0000-0001-6516-5322

Саицова Марина Аблулатиповна - $\Delta-р$ мед. наук, профр., рук. отА. ультразвуковых методов исследования. ORCID: 0000-0002-3233-1862 Куримина Эмла Влахимировна - врач-патологоанатом, зав. патологоанатомическим отА-нием. ORCID: 0000-0002-3208-534X

Имаев Тимур Эмвярович - $\Delta$-р меА. наук, сердечно-сосудистый хирург, гл. науч. сотр. отА. сердечно-сосудистой хирургии.

ORCID: 0000-0002-5736-5698 ${ }^{凶}$ Alexey E. Komlev. E-mail: pentatonika@bk.ru;
ORCID: 0000-0001-6908-7472

Marina D. Muksinova. ORCID: 0000-0001-6516-5322

Marina A. Saidova. ORCID: 0000-0002-3233-1862

Ella V. Kurilina. ORCID: 0000-0002-3208-534X

Timur E. Imaev. ORCID: 0000-0002-5736-5698 


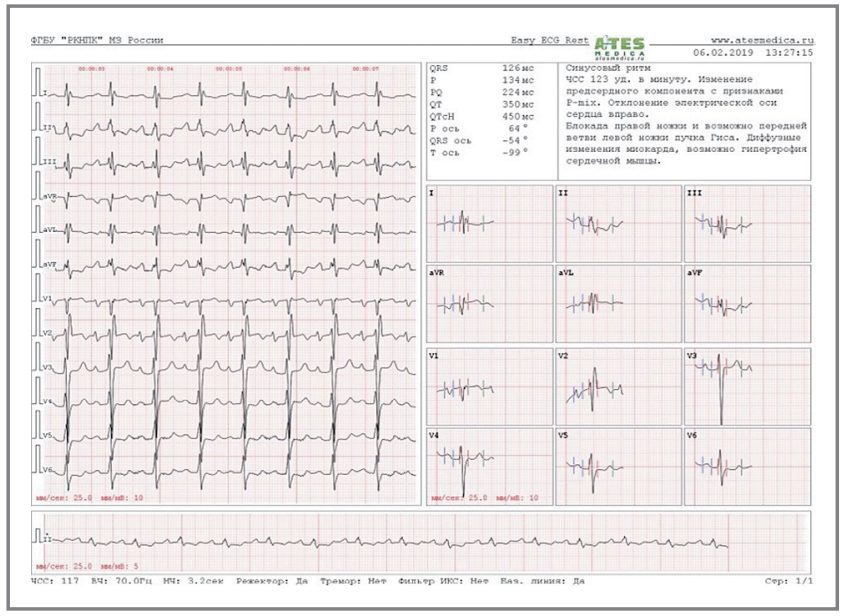

Рис. 1. ЭКГ при поступлении.

Fig. 1. Electrocardiogram on admission.

послеоперационном периоде осложнилась тяжелой правожелудочковой недостаточностью с проведением реанимационных мероприятий и последующим развитием вторичного СТ.

\section{КАинический случай}

Пациентка О., 69 лет, поступила 06.02.2019 в ФГБУ «НМИЦ кардиологии» с декомпенсацией сердечной недостаточности $(\mathrm{CH})$ по обоим кругам. Из анамнеза известно, что с рождения выявлен ДМЖП. В 1990 г. после экстракции зуба перенесла инфекционный эндокардит трикуспидального клапана, проводилась антибиотикотерапия с положительным эффектом. С 2010 г. начала отмечать нарастание одышки при физической нагрузке, неоднократно госпитализировалась по поводу декомпенсации СН. В сентябре 2018 г. госпитализирована в связи с декомпенсацией $\mathrm{CH}$, проводилась активная диуретическая терапия с положительным эффектом. Больная консультирована сердечно-сосудистыми хирургами: учитывая высокую легочную гипертензию (ЛГ), оперативное лечение в условиях искусственного кровообращения признано противопоказанным из-за крайне высокого периоперационного риска. До госпитализации в ФГБУ «НМИЦ кардиологии» принимала следующие препараты: торасемид - 10 мг/сут, спиронолактон - 50 мг/сут, бисопролол - 0,625 мг/сут, периндоприл - 5 мг/сут, розувастатин 20 мг/сут, ацетилсалициловую кислоту - 75 мг/сут.

При осмотре: бледность кожных покровов, цианоз губ, отеки нижних конечностей до колен. Отмечался усиленный сердечный толчок в пятом - шестом межреберье слева. При пальпации определялись диастолическое дрожание в четвертом межреберье слева у грудины и систолическое дрожание в области второго межреберья справа. При аускультации легких дыхание жесткое, ослабленное в нижних отделах легких, отмечаются влажные среднепузырчатые хрипы над всей поверхностью легких. Сатурация кислорода в крови при поступлении $76 \%$, в связи с чем начата кислородотерапия, поток кислорода установлен на 5 л/мин, на фоне чего сатурация увеличилась до $96 \%$. При аускультации сердца - грубый шум над всеми точками аускультации, который лучше выслушивается во II и V точке аускультации и проводится на сонные артерии. Над легочной артерией (ЛА) выслушивался убывающий дующий диастолический шум Грэхема-Стилла. Над мечевидным отростком выслушивался систолический шум, усиливающийся на
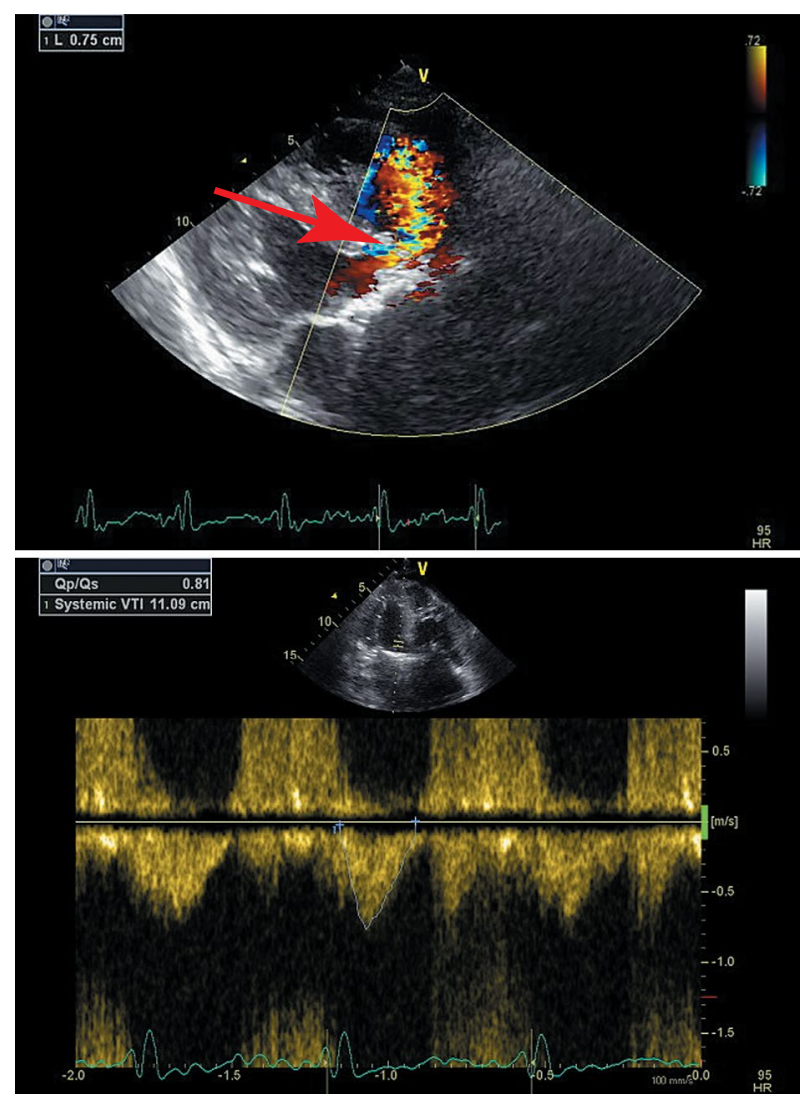

Рис. 2. ЭхоКГ при поступмении. Высокий Аефект внутрижекудочковой перегородки (указан стрелкой) с опрехелением соотношения мегочного и системного кровотока.

Fig. 2. Echocardiography (EchoCG) on admission. High intraventricular septum defect (indicated by the arrow) with determining the ratio of pulmonary and systemic blood flow.

вдохе. Пульс на лучевых артериях слабого наполнения, артерии стоп пальпировать не удалось из-за отечности. Артериальное давление (АД) 100/70 мм рт ст. Печень увеличена на 7 см, определяется гепатоюгулярный рефлюкс.

Электрокардиограмма (ЭКГ): синусовый ритм с частотой сердечных сокращений 123 уд/мин, отклонение электрической оси сердца вправо, изменение предсердного компонента с признаками P-mix, атриовентрикулярная блокада 1-й степени, блокада правой ножки и передней ветви левой ножки пучка Гиса (рис. 1).

Мультиспиральная компьютерная томография аорты: кальциноз трехстворчатого АК 4-й степени, размер фиброзного кольца $\mathrm{AK}-2,7 \times 3,4 \times 3,1 \times 3,0$ см. Определяется массивный кальцинат в проекции аортально-митрального контакта толщиной 0,6 см, протяженностью 2 см. Устье левой коронарной артерии расположено на 1,4 см, правой коронарной артерии - на 2 см выше фиброзного кольца АК. Диаметр аорты: на уровне синусов Вальсальвы $-3,7 \times 3,8 \times 3,9$ см, восходящий отдел $-3,6$ см, диаметр дуги $-2,4-2,5$ см. В области мембранозной части межжелудочковой перегородки (МЖП) визуализируется дефект (рис. 2).

По данным рентгенографии при поступлении 06.02.2019: венозный застой в легких 2-й степени, высокая артериальная ЛГ - коэффициент Мура 38\%, увеличена выпуклость (высота) легочного сегмента - 7 мм; увеличен коэффициент 


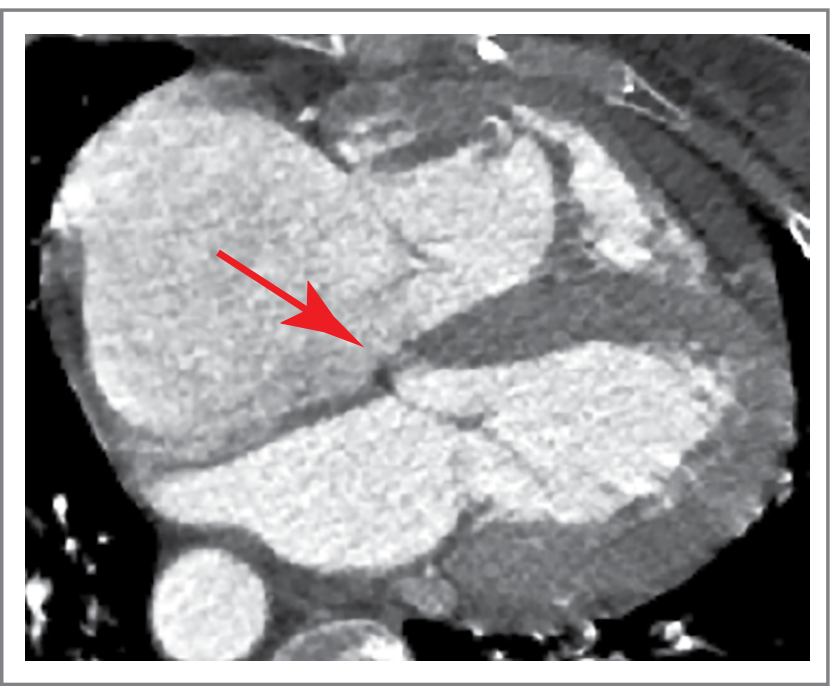

Рис. 3. Мукьтиспиральная компьютерная томография сердца с внутривенным контрастированием. Стрелкой указан дефект мембранозной части МЖП.

Fig. 3. Multispiral computed tomography of the heart with intravenous contrast. The arrow indicates the defect in the membranous part of interventricular septum.

Люпи - 42\%. Корни легких малоструктурны. Диффузный пневмосклероз. Увеличение ЛА до 24 мМ, левой ЛА - до 34 мм. В плевральных синусах: следовое количество двустороннего плеврального выпота. Сердце значительно расширено в поперечнике, ротировано, выбухает ствол ЛА. Наблюдается значительное увеличение правых отделов сердца, увеличение левого предсердия; левый желудочек (ЛЖ) оттеснен увеличенными правыми отделами кзади. Кардиоторакальный индекс (КТИ) - 69\%. Определяется выраженный кальциноз АК. Расширены верхняя полая и непарная вены. Задний вариант правосторонней дуги аорты.

По данным эхокардиографии (ЭхоКГ): АС тяжелой степени - максимальная скорость 4 м/с, средний систолический градиент на АК 40 мм рт. ст., площадь раскрытия (планиметрически) 0,6 см². Кальциноз АК 3-й степени. Аортальная недостаточность 2-й степени. Перимембранозный ДМЖП (диаметр около 7,5 мм) с двунаправленным сбросом крови, максимальный градиент давления между правым желудочком и ЛЖ - 50 мм рт. ст., соотношение легочного и системного кровотока $\mathrm{QP} / \mathrm{QS}=0,8$ (рис. 3). Высокая ЛГ (систолическое давление в ЛА - 103 мм рт. ст.), давление заклинивания ЛА - 19 мм рт. ст. Расширение обоих предсердий и правого желудочка (переднезадний размер 4,2 cм), TAPSE - 0,9 см. Выраженная концентрическая гипертрофия миокарда ЛЖ (толщина МЖП - 1,5 см). Сократимость ЛЖ относительно удовлетворительная, фракция выброса - 57\% (по Симпсону), конечно-диастолический размер ЛЖ - 4,4 см, ударный объем ЛЖ снижен (27 мл). В полости перикарда - до 120 мл жидкости. Признаки высокого центрального венозного давления.

Коронароангиография: правый тип коронарного кровоснабжения. Стеноз до 70\% в средней трети правой коронарной артерии. Левая коронарная артерия без значимых стенозов (рис. 4).

Магнитно-резонансная томография сердца (12.02.2019): выраженное расширение правых отделов сердца, гипертрофия миокарда обоих желудочков, парадоксальное движение МЖП. В фазово-контрастном режиме соотношение
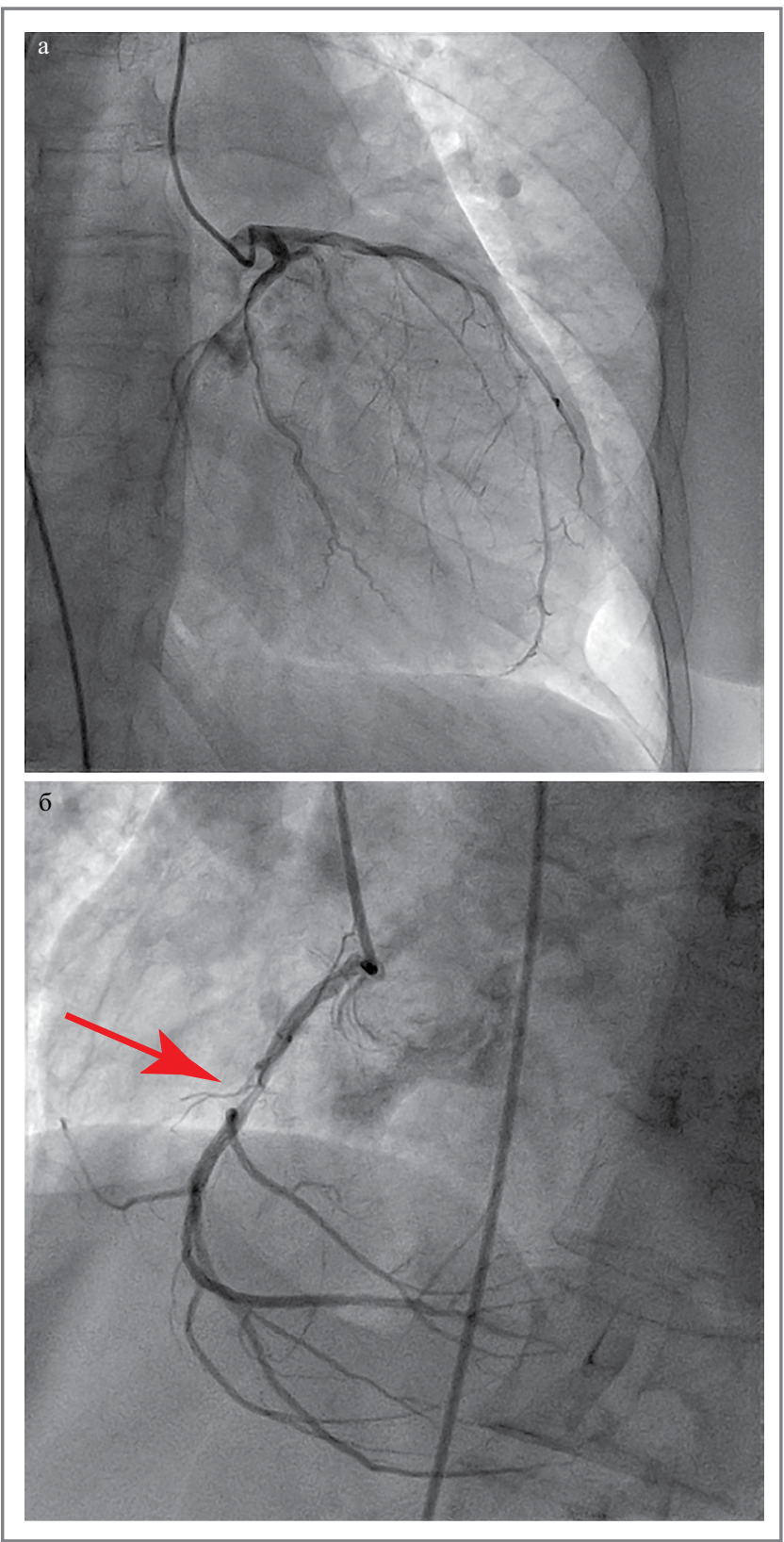

Рис. 4. Коронарограмма: а - левая коронарная артерия; б - правая коронарная артерия (стрелкой обозначен стеноз правой коронарной артерии).

Fig. 4. Coronary angiogram: a - left coronary artery; $b$ - right coronary artery (arrow indicates stenosis of the right coronary artery).

легочного и системного кровотока $2: 1$. Ствол ЛА и ее ветви значительно расширены: ствол ЛА - до 42 мм, правая ЛА до 38 мм, левая ЛА - до 30 мм. Гидроперикард с максимальной толщиной до 25 мм.

По данным лабораторных анализов: предсердный натрийуретический пептид - 3054 пг/мл, D-димер 1,42 мкг/мл, повышение печеночных трансаминаз (аланинаминотрансфераза - 54 ед/л, аспартатаминотрансфераза - 64 ед/л) и общего билирубина до 32,9 мкмоль/л, умеренная гипергликемия - 7,3 ммоль/л, креатинин 116 мкмоль/л (скорость клубочковой фильтрации по CKD-EPI - 41,49 мл/мин/1,73 м²). В общем анализе крови отмечался вторичный эритроцитоз до 5,59 млн/мкл и по- 
вышение гематокрита до 50\%. В анализе мочи - умеренная протеинурия $(0,67$ г/л).

Со дня поступления начата активная диуретическая терапия (фуросемид - 80 мг/сут внутривенно, спиронолактон - 50 мг), с помощью которой удалось достичь сбалансированного диуреза. С учетом тяжелого комбинированного порока сердца и артериальной гипотонии $\beta_{1}$-адреноблокаторы и ингибиторы ангиотензинпревращающего фермента не назначали. Для профилактики тромбоза назначен эноксапарин в профилактической дозе 40 мг.

11.02.2019 развился внезапный эпизод выраженной артериальной гипотонии, десатурации, послуживший причиной перевода в блок интенсивной терапии. Данный эпизод расценен как легочный гипертонический криз с острой правожелудочковой недостаточностью у больной с высокой ЛГ. Продолжены активная диуретическая терапия и кислородотерапия под контролем гемодинамики. Принимая во внимание наличие противопоказаний к пробе с вазодилататорами (тяжелый $\mathrm{AC}$ ) и межжелудочковый шунт, проведение катетеризации ЛА с целью оценки легочного сосудистого сопротивления решено не выполнять.

Тактика лечения пациентки обсуждена на врачебном консилиуме. В операции на открытом сердце (пластика ДМЖП и протезирование АК) по причине крайне высокого риска (высокая ЛГ, правожелудочковая дисфункция) пациентке отказано. В качестве паллиативного вмешательства по витальным показаниям принято решение о проведении транскатетерной коррекции АС с целью уменьшения давления в левых отделах сердца с обязательным сохранением межжелудочкового сообщения.

14.02.2019 выполнена транскатетерная имплантация АК биопротезом CoreValve Evolute ${ }^{\mathbb{B}} 34$ мм. Под эндотрахеальным наркозом выполнен доступ к правой бедренной артерии, а затем левой бедренной артерии, установлены интродьюсеры 6F. Через интродьюсер в левой бедренной артерии в корень аорты заведен диагностический катетер pigtail и выполнена диагностическая аортография. Через интродьюсер правой общей бедренной артерии в ЛЖ проведен жесткий проводник с диагностическим катетером. На супержестком проводнике в аортальную позицию подведен баллонный катетер. Выполнена баллонная предилатация АК. По супержесткому проводнику с помощью системы доставки в позицию АК доставлен и имплантирован биологический протез CoreValve Evolute ${ }^{\circledR} 34$ мм. Проведены постдилатация протеза AK баллоном NUMED 28 мм и контрольная ангиография: коронарные артерии проходимы, запирательная функция клапана осуществляется в полном объеме (рис. 5).

При интраоперационной катетеризации правых отделов сердца и ЛА после имплантации отмечено снижение систолического давления в ЛА с 110 до 84 мм рт. ст., по данным чреспищеводной ЭхоКГ - нормальная позиция протеза АК, умеренная парапротезная регургитация, уменьшение межжелудочкового шунтирования крови.

По данным рентгенографии органов грудной клетки от 14.02.2019, в послеоперационном периоде в отделении анестезиологии и реанимации сохранялся венозный застой 2-й степени, плевральные синусы свободны, КТИ 67\%.

В отделении анестезиологии и реанимации гемодинамика оставалась стабильной, отмечалось увеличение системного систолического АД до 130-140 мм рт. ст., в связи с чем 15.02.2019 пациентка переведена в палату хирургического отделения. Продолжались диуретическая терапия, антибиотикопрофилактика, прикроватное мониторирование ЭКГ.

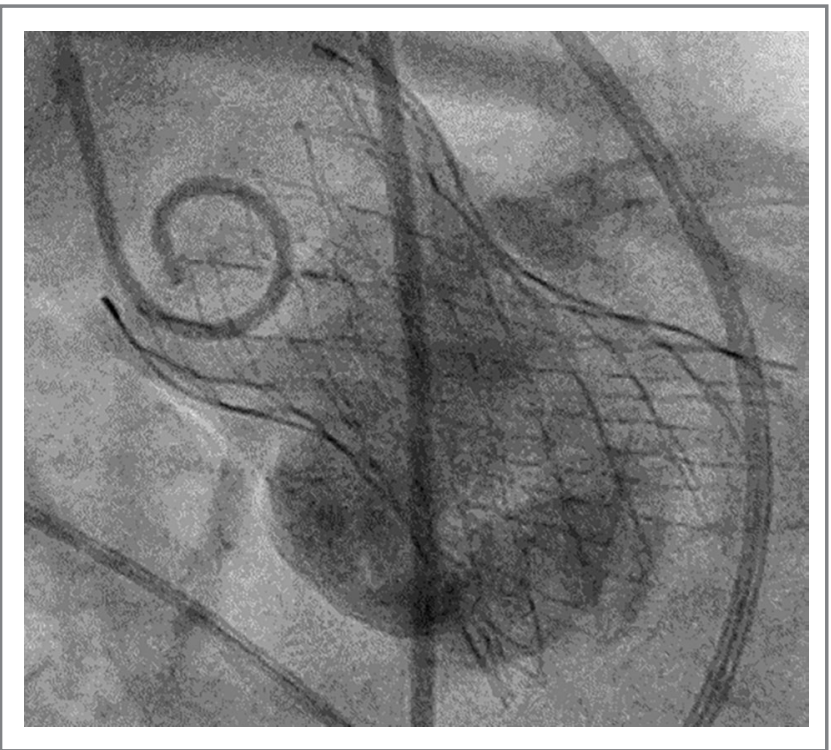

Рис. 5. Финальная интраоперационная аортография. В аортальной позиции установмен самораскрывающийся протез АK.

Fig. 5. Final intraoperative aortography. A selfexpanding aortic valve prosthesis is installed in the aortic position.

По данным рентгенографии органов грудной клетки от 16.02.2019 отмечалась положительная динамика в виде уменьшения степени застоя до 1-й степени, КТИ 69\%. В легких слева в нижней доле пневматизация снижена вследствие гиповентиляционных изменений.

Утром в 9:00 18.02.2019 произошли внезапная остановка кровообращения, асистолия, выполнены эффективные реанимационные мероприятия (непрямой массаж сердца, болюсное введение адреналина), интубация трахеи аппаратом искусственной вентиляции легких (ИВЛ). После восстановления гемодинамики в анализах крови отмечалось повышение тропонина до 1790,8 пг/мл, уровня трансаминаз (аспартатаминотрансфераза - 223,0 ед/л, аланинаминотрансфераза - 165,0 ед/л), креатинфосфокиназы - 98,00 Ед/л.

По данным ЭхоКГ от 18.02.2019: в проекции АК визуализируется биологический протез типа CoreValve, амплитуда раскрытия створок в полном объеме. Регургитация АК 1->2 степени, парапротезная фистула со стороны передней створки митрального клапана. Выраженное нарушение региональной сократимости ЛЖ: определяется зона акинезии средневерхушечных сегментов со стороны всех стенок ЛЖ, гиперкинез базальных сегментов (рис. 6). Глобальная сократимость ЛЖ умеренно снижена, фракция выброса - 38-40\% (по Симпсону). Сохраняется артериальная ЛГ, однако систолическое давление в ЛА снизилось до 80 мм рт. ст., т.е. стало меньше, чем при предыдущих исследованиях. Нижняя полая вена расширена, коллабирование ее снижено - признаки повышения центрального венозного давления. В области перимембранозной части МЖП определяется небольшой сброс крови слева направо (существенно меньше по сравнению с дооперационными данными - дефект частично прикрыт каркасом биопротеза). В полости перикарда патологического количества жидкости не выявлено.

Учитывая повышение уровня тропонина и трансаминаз, а также нарушение региональной сократимости по данным ЭхоКГ при отсутствии значимого поражения коро- 


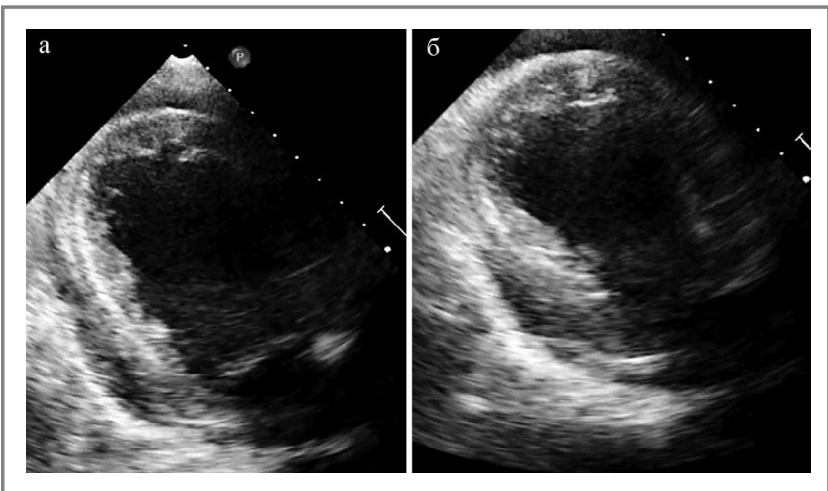

Рис. 6. ЭхоКГ после операции. Акинез средневерхушечных

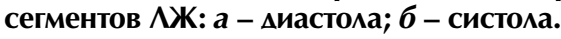

Fig. 6. EchoCG after surgery. Akinesis in the mid- and apical segments of left ventricle (LV): $\boldsymbol{a}$ - diastole; $\boldsymbol{b}$ - systole.

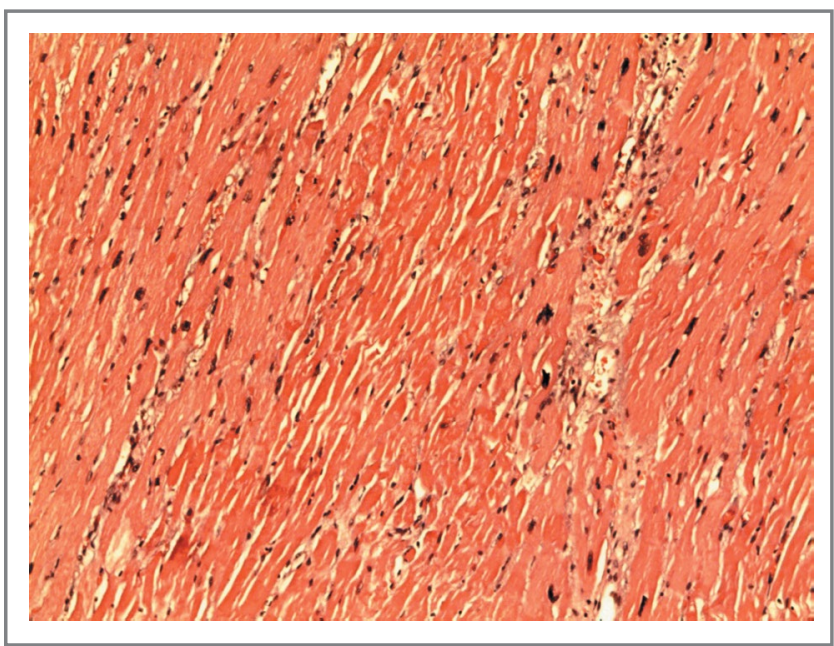

Рис. 7. Зона коагуляционного некроза миокарда без выраженного Аемаркационного вала, с резким расширением и полнокровием сосудов в пограничной области. Окраска гематоксикином и эозином. $\times 100$.

Fig. 7. Coagulative myocardial necrosis zone without a marked demarcation shaft, with a sharp expansion and plethora of vessels in the border area. Staining with hematoxylin and eosin. $\times 100$.

нарных артерий, появление распространенных зон нарушения региональной сократимости расценено как СТ. В терапию включены $\beta$-адреноблокаторы длительного действия.

В 0:05 19.02.2019 - эпизод брадикардии с переходом в асистолию, падением гемодинамики АД до 40/20 мм рт. ст., неэффективной электрокардиостимуляцией, начаты реанимационные мероприятия: ИВЛ: $100 \%-\mathrm{O}_{2}$, непрямой массаж сердца, коррекция временного электрода электрокардиостимулятора, внутривенно болюсно введено: адреналин 1:20 3 раза, солумедрол 1000 мг, 4\% натрия бикарбонат 100 мл внутривенно, 10\% хлористый кальций 10 мл, инфузия допамина 8 мкг/кг/мин. В течение 10 мин восстановлена гемодинамика, частота сердечных сокращений 130/мин, АД 145/40 мм рт. ст. Периодически отмечались эпизоды брадикардии до 48 уд/мин и срабатывание временного электрокардиостимулятора. Проводилась инотропная поддержка: допамин 8 мкг/кг/мин, адреналин 80-100 нг/кг/мин. По назогастральному зонду определялось отделяемое по типу «кофейной гущи».

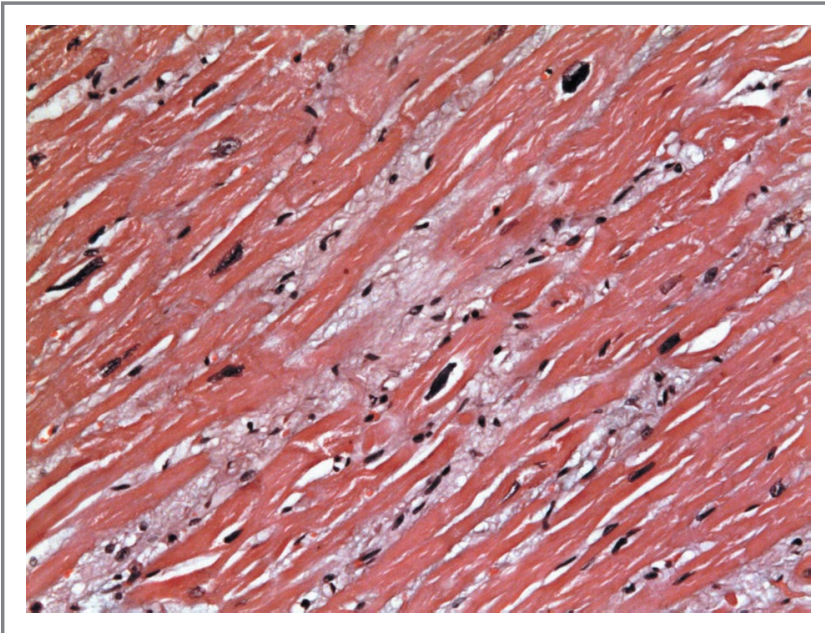

Рис. 8. Аифффузый отек стромы миокарда с мукоидизацией. $\Delta$ иффузная умеренно выраженная лимфоцитарно-макрофагальная инфимьтрация стромы. Очаговый миоцитолизис. Гипертрофия кардиомиоцитов. Окраска гематоксихином и эозином. $\times 200$.

Fig. 8. Diffuse myocardial stromal edema with mucoidization. Diffuse moderate lymphocytic-macrophage infiltration of the stroma. Focal myocytolysis. Hypertrophy of cardiomyocytes. Staining with hematoxylin and eosin. $\times 200$.

В 6:00 19.02.2019 на фоне нарастающего лактатацидоза, олигурии и артериальной гипотонии отмечались брадикардия и электромеханическая диссоциация, в связи с чем начат непрямой массаж сердца, ИВЛ 100\% кислородом, введено: атропин - 1 мг, адреналин через перфузор 200 нг/кг/мин, допамин - 10 мг/кг/мин, сода 4\% - 200 мл, хлорид кальция - 20 мл, Солу-Медрол - 1 г. Через 20 мин реанимационных мероприятий восстановлен синусовый ритм, однако в 8:00 на фоне нарастающей сердечно-сосудистой недостаточности, анурии наступили остановка кровообращения, асистолия. Реанимационные мероприятия без эффекта. В 8:35 19.02.2019 констатирована биологическая смерть.

При патологоанатомическом вскрытии отмечена выраженная гипертрофия сердца (масса 540 г) с дилатацией полостей преимущественно правых отделов. В просвете АК в функционально правильном положении установлен биопротез, створки его подвижны. Нижний край каркаса расположен на 2 см ниже фиброзного кольца клапана. Створки АК с выраженным склерозом, кальцинозом. Под фиброзным кольцом клапана в проекции МЖП имеется сквозной щелевидный дефект, с плотными склерозированными краями, размерами около 1,0×0,4 см. Миокард во всех областях дряблый, отечный, на разрезах - с очагами неравномерного кровенаполнения. В задней стенке ЛЖ интрамурально имеется очаг размягчения миокарда размерами $4 \times 1 \times 1 \mathrm{~cm}$, пропитанный кровью, с четкими контурами. По латеральной поверхности в верхней части, интрамурально, - участок размягчения миокарда белесоватого цвета с относительно четкими контурами с перифокальным полнокровием, размерами $4 \times 3$ см. В толще всех сегментов миокарда определяются множественные соединительнотканные прослойки. Просвет ствола и начального отдела огибающей артерии сужен до 40\% за счет плотных атеросклеротических бляшек. Субинтимально в этой области - сливающиеся темно-красные очаговые кровоизлияния. Просвет правой коронарной 


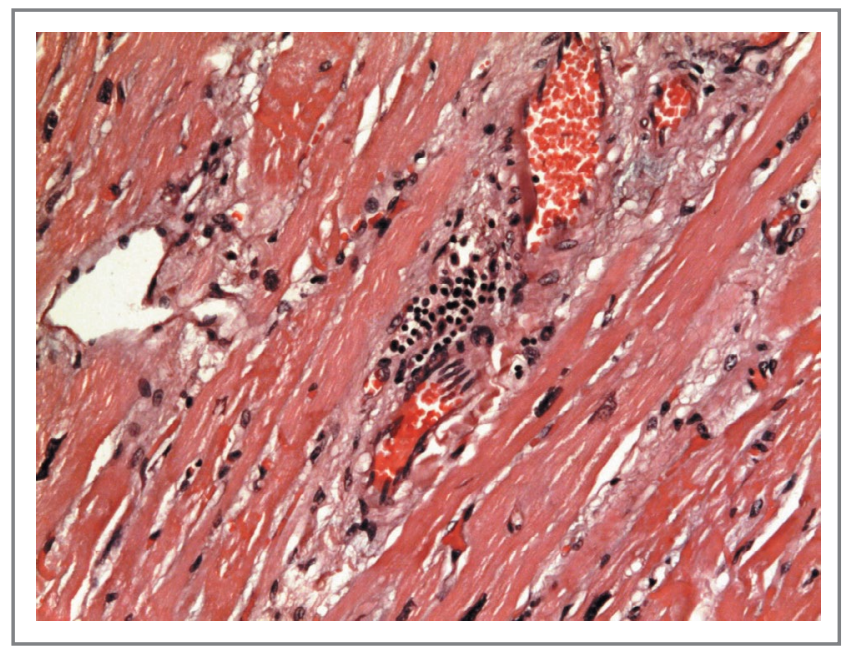

Рис. 9. Очаговый лимфоцитарный инфияьтрат в строме миокарда. Отек стромы миокарда. Коагуяяционный некроз отдекьных групп кардиомиоцитов. Гипертрофия кардиомиоцитов. Расширение и полнокровие венозных сосудов. Слацж-феномен. Окраска гематоксилином и эозином. $\times 200$.

Fig. 9. Focal lymphocytic infiltration in the myocardial stroma. Myocardial stromal edema. Coagulative necrosis of certain groups of cardiomyocytes. Hypertrophy of cardiomyocytes. Expansion and plethora of venous vessels. Sludge phenomenon. Staining with hematoxylin and eosin. $\times 200$.

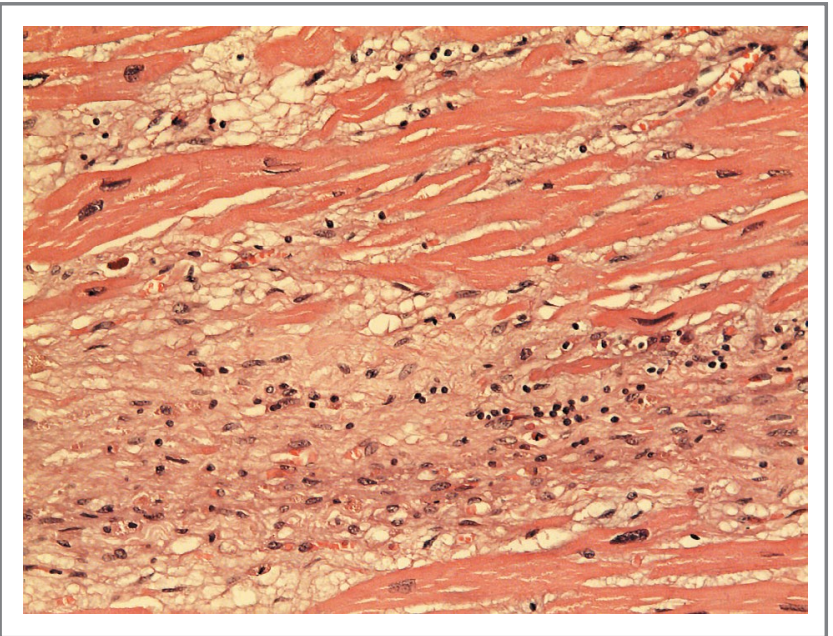

Рис. 10. Участок кардиосклероза с разрыхлением и отеком фиброзной ткани, Аиффузной Аимфогистиоцитарной инфикьтрацией. Резко выраженный отек стромы. Полнокровие капимляров. Коагулящионный некроз отАельных кардиомиоцитов. Гипертрофия кардиомиоцитов. Окраска гематоксикином и эозином. $\times \mathbf{2 0 0}$.

Fig. 10. Area of cardiosclerosis with loosening and edema of fibrous tissue, diffuse lymphohistiocytic infiltration. Pronounced stromal edema. Capillary congestion. Coagulative necrosis of individual cardiomyocytes. Hypertrophy of cardiomyocytes. Staining with hematoxylin and eosin. $\times 200$.

артерии сужен на протяжении плотными атеросклеротическими бляшками, до 50-70\%, в дистальном отделе облитерирован. Дистальная часть огибающей артерии сужена плотными атеросклеротическими бляшками до $30-50 \%$.

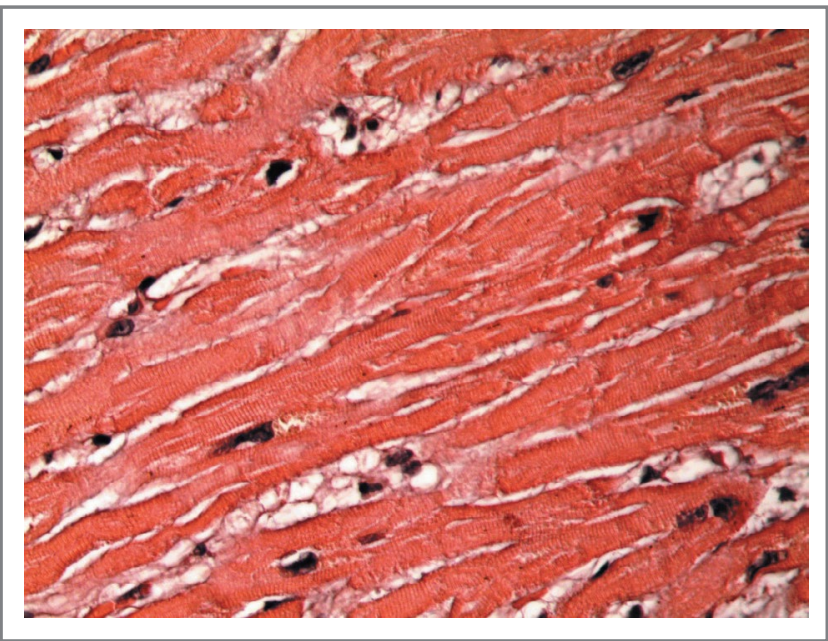

Рис. 11. Подчеркнутая поперечная исчерченность

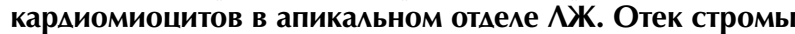
миокарда. Окраска гематоксикином и эозином. $\times \mathbf{4 0 0}$.

Fig. 11. Emphasized transverse striation of cardiomyocytes in the apical part of left ventricle. Myocardial stromal edema. Staining with hematoxylin and eosin. $\times 400$.

При гистологическом исследовании в миокарде задней стенки ЛЖ найден очаг коагуляционного некроза без выраженного демаркационного вала, с резким расширением и полнокровием сосудов в пограничной области (рис. 7). В разных отделах ЛЖ обнаружены выраженная гипертрофия кардиомиоцитов, диффузный отек стромы миокарда, местами с мукоидизацией, диффузная умеренно выраженная лимфоцитарно-макрофагальная инфильтрация стромы; очаговый миоцитолизис и коагуляционный некроз отдельных групп кардиомиоцитов, очаговые лимфогистиоцитарные инфильтраты, расширение и полнокровие венозных сосудов, сладж-феномен (рис. 8, 9). Имелись участки кардиосклероза с разрыхлением и отеком фиброзной ткани, с диффузной лимфогистиоцитарной инфильтрацией (рис. 10). В кардиомиоцитах апикального отдела ЛЖ отмечена выраженная поперечная исчерченность кардиомиоцитов (рис. 11).

Морфологические данные подтвердили наличие инфаркта миокарда, давность которого, учитывая отсутствие сформированного демаркационного вала, составляет менее 1 сут. К изменениям, характерным для СТ, следует отнести выраженный диффузный отек стромы миокарда с признаками мукоидизации, умеренно выраженную диффузную и очаговую инфильтрацию стромы миокарда клетками мононуклеарного ряда. Эти данные соответствуют сведениям, опубликованным в литературе [8]. Подчеркнутая поперечная исчерченность кардиомиоцитов в апикальных отделах сердца считается проявлением гиперрелаксации саркомеров, свойственной ишемизированным участкам миокарда ЛЖ, дающим эффект баллонной деформации апикальной области вследствие акинезии стенки ЛЖ. Выраженное полнокровие венозных отделов микроциркуляторного русла, полнокровие капилляров и сладж-феномен характеризуют проявления острой $\mathrm{CH}$.

\section{Обсужмение}

Особенностью приведенного наблюдения является сложный генез СН: врожденный ДМЖП и тяжелый АС взаимно усугубляли друг друга и в совокупности предопределяли неблагоприятный прогноз. Изначально ДМЖП компенсиро- 
ван, но с развитием АС и увеличением конечно-диастолического давления в ЛЖ увеличилось лево-правое шунтирование крови через ДМЖП, наросла степень ЛГ и произошла реверсия потока через ДМЖП с формированием неполного синдрома Эйзенменгера. При принятии решения об операции мы полагали, что транскатетерное протезирование АК позволит в некоторой степени скомпенсировать сложные нарушения кровообращения: коррекция АC, по нашему мнению, должна была привести к уменьшению давления заполнения ЛЖ, уменьшению лево-правого сброса и увеличению шунта справа налево. Учитывая полученные данные об отношении легочного и системного кровотока, однозначно предполагалось сохранить межжелудочковое сообщение, поскольку наличие вено-артериального сброса крови даже при высокой резидуальной ЛГ обеспечивает лучший послеоперационный прогноз у пациентов с врожденными пороками сердца $[9,10]$. Однако в действительности частичное закрытие дефекта МЖП каркасом протеза АК в ходе коррекции АC ограничило компенсаторные возможности вено-артериального шунтирования, что спровоцировало развитие легочного гипертензионного криза. На фоне гиперадренергического нейрогуморального статуса, чему способствовало использование инотропной поддержки при реанимационных мероприятиях, развился вторичный СТ. Последующие рецидивирующие эпизоды остановки кровообращения и реанимационные мероприятия, замыкая порочный круг, привели к дальнейшему усугублению гемодинамических расстройств и в конечном итоге - к летальному исходу.

Дополнительным фактором неблагоприятного прогноза стало развитие СТ, диагноз которого установлен согласно как критериям клиники Майо [11], так и новым критериям InterTak Registry [12]. По-видимому, СТ развился после реанимационных мероприятий с использованием массивной инотропной поддержки. Среди причин развития стрессиндуцированного повреждения миокарда следует также предполагать сам факт оперативного вмешательства [13] и особенно легочный гипертонический криз с острой правожелудочковой недостаточностью, развившийся вследствие нарушения компенсаторного право-левого сброса крови с связи с частичным перекрытием МЖП [14].

Вопросы этиопатогенеза и лечения СТ на сегодняшний день остаются малоизученными. Имеются указания, что СТ может являться как причиной, так и следствием остановки сердца [15]. Гиперадренергическая среда (эндогенная или ятрогенная), связанная с остановкой кровообращения, может провоцировать развитие СТ, а такие особенности патогенеза СТ, как удлинение скорректированного интервала $Q T(Q T c)$ и диффузный отек миокарда, могут выступать в качестве морфофункционального субстрата жизнеугрожающих желудочковых аритмий $[16,17]$. По данным субанализа регистра пациентов с CT, остановка сердца возникала в среднем в течение 1 сут (IQR 0-3 дней) и ассоциировалась с высокой внутрибольничной смертностью - 35\% (у пациентов с СТ без остановки сердца $-2,4 \%, p<0,001)$ [18].

Рассматриваемый клинический пример иллюстрирует сложность принятия решения о тактике лечения больных с сочетанием врожденной и приобретенной патологий сердца. Вероятно, вторичный СТ в данном случае можно расценивать как маркер критического изменения внутрисердечной гемодинамики при ятрогенном воздействии на степень межжелудочкового шунтирования. Гипотетическим механизмом опосредования связи между уменьшением внутрижелудочкового сброса крови и развитием острой дисфункции ЛЖ может быть гиперконтрактильность ЛЖ в условиях резкого снижения преднагрузки с последующей акинезией апикальных сегментов миокарда.

\section{Заключение}

У пациентов кардиохирургического профиля вторичный СТ является одной из частых причин развития острой СН в раннем послеоперационном периоде [19], а также возможным предиктором неблагоприятного прогноза в критическом состоянии. Нельзя исключить, что в случаях развития данного синдрома, ассоциированных с коррекцией структурной патологии сердца, одним из компонентов этиопатогенеза является резкое изменение гемодинамических условий функционирования миокарда («миокардиальный стресс»). Необходимы накопление и анализ клинического опыта лечения пациентов с вторичным СТ, связанного с кардиохирургическими вмешательствами и их анестезиолого-реаниматологическим сопровождением.

Конфликт интересов. Авторы заявляют об отсутствии конфликта интересов.

Conflict of interests. The authors declare no conflict of interest.

\section{Список сокрашений}

АД - артериальное давление

АК - аортальный клапан

$\mathrm{AC}$ - аортальный стеноз

ДМЖП - дефект межжелудочковой перегородки

ИВЛ - искусственная вентиляция легких

КТИ - кардиоторакальный индекс

ЛА - легочная артерия

ЛГ - легочная гипертензия

ЛЖ - левый желудочек

МЖП - межжелудочковая перегородка

$\mathrm{CH}$ - сердечная недостаточность

СТ - синдром Такоцубо

ЭКГ - электрокардиограмма

ЭхоКГ - эхокардиография

\section{АИТЕPATYPA/REFERENCES}

1. Prasad A, Dangas G, Srinivasan $M$, et al. Incidence and angiographic characteristics of patients With apical ballooning syndrome (takotsubo/stress cardiomyopathy) in the HORIZONSAMI trial. Cathet Cardiovasc Intervent. 2013;83(3):343-8. DOI:10.1002/ccd.23441

2. Bybee K, Prasad A, Barsness G, et al. Clinical characteristics and Thrombolysis In Myocardial Infarction frame counts in women with transient left ventricular apical ballooning syndrome. Am J Cardiol. 2004;94(3):343-6. DOI:10.1016/j.amjcard.2004.04.030
3. Redfors $\mathrm{B}$, Vedad R, Angerås $\mathrm{O}$, et al. Mortality in takotsubo syndrome is similar to mortality in myocardial infarction - A report from the SWEDEHEART registry. Int J Cardiol. 2015;185:282-9. DOI:10.1016/j.ijcard.2015.03.162

4. Templin C, Ghadri J, Diekmann J, et al. Clinical Features and Outcomes of Takotsubo (Stress) Cardiomyopathy. $N$ Engl J Med. 2015;373(10):929-38. DOI:10.1056/nejmoa1406761

5. Y-Hassan S. Clinical features and outcome of epinephrine-induced takotsubo syndrome: Analysis of 33 published cases. Cardiovasc Revasc Med. 2016;17(7):450-5. DOI:10.1016/j.carrev.2016.07.005 
6. Abraham J, Mudd J, Kapur N, et al. Stress Cardiomyopathy After Intravenous Administration of Catecholamines and BetaReceptor Agonists. J Am Coll Cardiol. 2009;53(15):1320-5. DOI:10.1016/j.jacc.2009.02.020

7. Ansari U, El-Battrawy I, Fastner C, et al. Clinical outcomes associated with catecholamine use in patients diagnosed with Takotsubo cardiomyopathy. BMC Cardiovasc Disord. 2018;18(1). DOI:10.1186/s12872-018-0784-6

8. Mitchell A, Marquis F. Can takotsubo cardiomyopathy be diagnosed by autopsy? Report of a presumed case presenting as cardiac rupture. $B M C$ Clin Pathol. 2017;17(1). DOI:10.1186/s12907-017-0045-0

9. Manes A, Palazzini M, Leci E, et al. Current era survival of patients with pulmonary arterial hypertension associated with congenital heart disease: a comparison between clinical subgroups. Eur Heart $J$. 2013;35(11):716-24. DOI:10.1093/eurheartj/eht072

10. Galiè N, Humbert M, Vachiery J, et al. 2015 ESC/ERS Guidelines for the diagnosis and treatment of pulmonary hypertension. Eur Heart $J$. 2015;37(1):67-119. DOI:10.1093/eurheartj/ehv317

11. Prasad A, Lerman A, Rihal C. Apical ballooning syndrome (Tako-Tsubo or stress cardiomyopathy): A mimic of acute myocardial infarction. Am Heart J. 2008;155(3):408-17. DOI:10.1016/j.ahj.2007.11.008

12. Ghadri J, Wittstein I, Prasad A, et al. International Expert Consensus Document on Takotsubo Syndrome (Part I): Clinical Characteristics, Diagnostic Criteria, and Pathophysiology. Eur Heart J. 2018;39(22):2032-46. DOI:10.1093/eurhearti/ehy076

13. Harhash A, Koulogiannis K, Marcoff L, et al. Cardiomyopathy After Transcatheter Aortic Valve Replacement. JACC Cardiovasc Interv. 2016;9(12):1302-4. DOI:10.1016/j.jcin.2016.04.017
14. Floras J, Ponikowski P. The sympathetic/parasympathetic imbalance in heart failure with reduced ejection fraction. Eur Heart $J$. 2015;36(30):1974-82. DOI:10.1093/eurheartj/ehv087

15. Madias J. Cardiac arrest-triggered takotsubo syndrome vs. takotsubo syndrome complicated by cardiac arrest. Int J Cardiol. 2016;225:142-3. DOI:10.1016/j.ijcard.2016.09.090

16. Madias C, Fitzgibbons T, Alsheikh-Ali A, et al. Acquired long QT syndrome from stress cardiomyopathy is associated with ventricular arrhythmias and torsades de pointes. Heart Rhythm. 2011;8(4):555-61. DOI:10.1016/j.hrthm.2010.12.012

17. Migliore F, Zorzi A, Perazzolo Marra M, et al. Myocardial edema as a substrate of electrocardiographic abnormalities and life-threatening arrhythmias in reversible ventricular dysfunction of takotsubo cardiomyopathy: Imaging evidence, presumed mechanisms, and implications for therapy. Heart Rhythm. 2015;12(8):1867-77. DOI:10.1016/j.hrthm.2015.04.041

18. Gili S, Cammann V, Schlossbauer S, et al. Cardiac arrest in Takotsubo syndrome: results from the InterTAK Registry. Eur Heart $J$ 2019;40(26):2142-51. DOI:10.1093/eurheartj/ehz170

19. Lyon A, Bossone E, Schneider B, et al. Current state of knowledge on Takotsubo syndrome: A Position Statement from the Taskforce on Takotsubo Syndrome of the Heart Failure Association of the European Society of Cardiology. Eur J Heart Fail. 2015;18(1):8-27. DOI:10.1002/ejhf.424

Статья поступила в редакцию / The article received: 13.01.2021 